\title{
Pacientes que rehúsan el tratamiento antirretroviral en el medio penitenciario
}

\author{
L Sordo-del Castillo $^{1}$, I Ruiz-Pérez ${ }^{2,3}$, A Olry-Labry de Lima ${ }^{2,3}$, \\ JM Soto-Blanco ${ }^{4,3}$, JJ Antón-Basanta ${ }^{5}$, E Girela-López ${ }^{6}$, JM Castro-Recio ${ }^{7}$
}

${ }^{1}$ Servicio de Medicina Preventiva. Hospital Universitario Virgen de las Nieves de Granada. Av. Fuerzas Armadas 2. 18010 Granada. Tel. 958020543.

${ }^{2}$ Escuela Andaluza de Salud Pública. Campus Universitario de Cartuja, Apdo. de correos 2070, CP 18080 Granada, España. Tel. 958027 510, fax +34.958 027503.

${ }^{3}$ Ciber Epidemiología y Salud Publica (CIBERESP).

${ }^{4}$ Servicio Medicina Intensiva. Hospital Clínico Universitario San Cecilio. Granada. Av. Dr. Olóriz 16. Granada 18012.

${ }^{5}$ Servicio Médico Centro Penitenciario de Albolote, Granada. Centro Penitenciario de Albolote. Ctra. Comarcal 220, Km. 6. 18220 Albolote.

${ }^{6}$ Servicio Médico Centro Penitenciario de Córdoba. Av. Madrid-Cádiz, Km 391. 14015 Córdoba.

${ }^{7}$ Servicio Médico Centro Penitenciario de Huelva. La Ribera, s/n. 21610-Huelva.

\section{RESUMEN}

Introducción: En los estudios existentes sobre pacientes VIH+ la población a estudio ha sido tomada de manera homogénea, sin diferenciar aquella que cumple los requerimientos terapéuticos de la que no lo hace. Quizás por la dificultad en el acceso al grupo de pacientes que rehúsan el tratamiento antirretroviral. El medio penitenciario nos permite acceder a esta población, hasta hoy no estudiada. El objetivo de este estudio es describir el estado clínico y psicosocial de los reclusos seropositivos que rehúsan el TARV, comparándolo con el de aquellos que sí están en TARV o no se les indica tomarlo.

Métodos: Estudio transversal con 585 reclusos VIH positivos ingresados en tres prisiones andaluzas entre mayo-julio de 2004. Como variable de agrupación se empleó rehusar el TARV, tomarlo o no hacerlo por no estar indicado. Como independientes se incluyeron sociodemográficas, psicosociales, clínicas y relacionadas con el medio penitenciario.

Resultados: El 16,8\% de los reclusos rehusaban el TARV, mientras el 56,3\% estaban en tratamiento y al $26,8 \%$ no le estaba indicado. Entre los reclusos que rehusaban el TARV aparece una mayor prevalencia de coinfección por VHC, mayor consumo intrapenitenciario de opiáceos y tratamiento con metadona, más juicios pendientes y más entradas en prisión.

Conclusiones: Estos resultados ponen de relieve la existencia de un grupo poblacional, accesible gracias al medio penitenciario, con características propias que no sigue las indicaciones terapéuticas y que representa un riesgo no sólo para su salud, sino para la de la comunidad.

Palabras clave: VIH, Impacto Psicosocial, Terapia Antirretroviral, Prisiones, Negativa al Tratamiento, Prisiones.

\section{PATIENTS WHO REFUSE ANTIRETROVIRAL TREATMENT IN PRISON}

\section{ABSTRACT}

Introduction: Current studies of HIV+ patients in the prison population have been carried out without considering differences that might exist between patients who accept retroviral treatment and those who do not. One possible reason for this may be the difficulty in gaining access to patients who refuse antiretroviral treatment. However, the prison environment makes it possible to locate and study this type of patient, who up till now has not been the subject of study. The aim of this article is to describe the clinical and psychosocial state of HIV+ inmates who refuse ARVT and compare this data with patients receiving treatment and others for whom treatment has not been indicated.

Methods: Cross-sectional study using $585 \mathrm{HIV}+$ inmates in three prisons in Andalusia from May to June 2004. Refusal, acceptance and non-indication of ARVT treatment was the grouping variable used. The independent variables were socio-demographic, psychosocial, clinical and other variables relating to the prison environment.

Results: $16.8 \%$ of patients refused ARVT, while $56.3 \%$ were receiving treatment and another 26.8 were not indicated 
for any medication. Amongst the patients that refused ARVT there was a greater prevalence of HIV co-infection, higher inprison consumption of opiates and methadone treatment, more cases pending and higher rates of recidivism.

Conclusions: these results highlight the existence of a group with unique characteristics that is accessible thanks to the special conditions within the prison environment. It is a group that chooses not to follow therapeutic indications and which represents a risk factor not only for its own health, but also for the community at large.

Key words: HIV, Psychosocial Impact, Antiretroviral Therapy, Prison, Refusal to Treatment, Prison.

Texto recibido: abril 2007

Texto aceptado: octubre 2007

\section{INTRODUCCIÓN}

Para el paciente con infección por el virus de la inmunodeficiencia humana (VIH) la aparición de la terapia antirretroviral de gran actividad (TARGA) ha supuesto la posibilidad de cambiar la evolución de su enfermedad, llegando a considerarse una enfermedad crónica ${ }^{1,2}$. Ello no sólo beneficia al paciente infectado, sino que condiciona la disminución de las enfermedades oportunistas relacionadas que, como la tuberculosis, son transmisibles a toda la comunidad.

En España el número de personas encarceladas ha sufrido un incremento del $38 \%$ en la última década. La población reclusa es actualmente de 62.794 personas, de las cuales 13.396 están en los centros penitenciarios andaluces ${ }^{3}$. El 15\% de la misma está infectada por el virus $\mathrm{VIH}^{4}$, suponiendo este dato la prevalencia más alta de los países europeos ${ }^{5}$.

En torno al $52 \%$ de los reclusos VIH+ españoles se encuentran en tratamiento antirretroviral ${ }^{5}$ (TARV). Las oportunidades y las condiciones terapéuticas que encontramos en las cárceles españolas, no difieren de las de la población en libertad. Así, las recomendaciones respecto al inicio del mismo son iguales en el medio penitenciario y extrapenitenciario $^{6}$, estando basadas en España en las consensuadas por el Grupo de Estudio de SIDA (GESIDA) y del Plan Nacional sobre el SIDA (PNS) ${ }^{7}$. Así, la decisión de iniciar TARV debe basarse en tres elementos: la sintomatología, el recuento de linfocitos CD4+ y la carga viral plasmática. Se trata sólo de una recomendación, ya que el inicio del tratamiento queda supeditado a la valoración del médico, y por supuesto al paciente que tiene la libertad de seguir estas recomendaciones. Todo esto hace que queden definidos tres grupos de pacientes: aquellos que están en TARV, aquellos que no lo están porque no le esta indicado, y aquellos que rehúsan tomarlo a pesar de serles indicado.

En la última década se ha incrementado el estudio de los reclusos VIH+. Algunos de estos estudios han puesto de manifiesto diferencias existentes respecto a los realizados en el medio hospitalario ${ }^{8}$. Aquellos centrados en las características psicosociales han observado en la población penitenciaria una mayor frecuencia de morbilidad psíquica, menor nivel sociocultural o una mayor prevalencia de adicción a opiáceos que en la población general seropositiva9. Sin embargo, en todos estos estudios se ha tomado a todo el colectivo de reclusos VIH+ de manera homogénea, sin hacer diferenciación entre aquellos que cumplen los requerimientos terapéuticos y los que no lo hacen. Esta misma carencia es achacable a la investigación hospitalaria, con la diferencia de que en este último caso el acceso a la población que rehúsa el TARV está muy restringido, ya que acuden menos a consulta y a las farmacias. Sin embargo, el medio penitenciario nos permite acceder a esta población, hasta hoy no estudiada, población importante no sólo por las implicaciones que su decisión de rechazar el TARV tiene sobre su salud, sino también por suponer un riesgo para la salud pública como posible reservorio de infecciones oportunistas, más aún en el contexto de una institución cerrada y en una población con alta prevalencia de inmunodepresión. Además, una vez cumplida su pena, que en ocasiones es conmutada por enfermedad grave ${ }^{10}$, como lo es el SIDA, estos pacientes se reintegran a la sociedad con los problemas que esto implica.

El objetivo de este estudio es describir el estado clínico y psicosocial de los reclusos seropositivos que rehúsan el tratamiento antirretroviral y compararlo con el de aquellos que sí están en TARV o no se les indica tomarlo, en tres prisiones andaluzas (Córdoba, Granada y Huelva).

\section{MATERIAL Y MÉTODOS}

Se realizó un estudio transversal a todos aquellos reclusos VIH positivos ingresados en los Centros Penitenciarios de Albolote (Granada), Córdoba y Huel- 
va entre mayo-julio de 2004. Fueron excluidos del estudio todos aquellos cuyo estado físico o mental hizo imposible la realización de las entrevistas y la cumplimentación de los cuestionarios. Se dispuso de información de un total de 585 sujetos, (tasa de respuesta: $96.05 \%)$.

\section{Las variables estudiadas:}

Como variable de agrupación se empleó rehusar el TARV, tomarlo o no hacerlo por no estar indicado. Como variables independientes se incluyeron las siguientes:

1. Variables sociodemográficas: Edad (años), sexo, hijos, nivel educativo (No sabe ni leer ni escribir, primarios incompletos, primarios-EGB, F.P-Bachillerato-BUP-universidad).

2. Variables psicosociales: número de visitas recibidas al mes (ninguna, de una a tres, más de tres), personas que le visitan con más frecuencia (pareja, hijos/as, parientes y familiares, amistades, otras), existencia de apoyo social dentro (No, Sí: Otros internos, profesionales que trabajan en el centro, miembros de alguna ONG y otras) y fuera de la prisión (No, Sí: pareja, hijos/as, parientes y familiares, amistades, otras).

3. Variables relacionadas con las drogas: droga más frecuentemente consumida (Heroína más cocaína, heroína sola, cocaína sola, metadona, psicofármacos, hachís) en la cárcel y en la calle, y tiempo de consumo de drogas, excluidas legales y derivados del cáñamo.

4. Variables clínicas: $\mathrm{CD} 4\left(\mathrm{cel} / \mathrm{mm}^{3}\right)$, carga viral (copias/ml), SIDA, tiempo desde que se sabe portador de anticuerpos (meses), coinfección con VHC y presencia de otras enfermedades crónicas.

5. Variables del medio penitenciario: situación penal, causa de ingreso, tiempo de condena, numero de entradas en prisión, calidad de la comida, recibir suplementos alimenticios (leche, batidos, etc.).

6. Otras: presencia de morbilidad psíquica y salud autopercibida: percepción del estado de salud respecto al año anterior (mejor, igual, peor) e ingreso o encamamiento en los últimos seis meses (sí, no).

\section{Instrumentos de medición:}

Para medir la morbilidad psíquica se usó el General Health Questionnary de 12 ítems que ha sido adaptado y validado en nuestro medio ${ }^{11}$. Se trata de un cuestionario autoadministrado. Este instrumento considera paciente con morbilidad psíquica, aquel que obtiene una puntuación igual o mayor a tres. $\mathrm{Pa}$ ra el punto de corte establecido de 6/7, el instrumen- to tiene una sensibilidad de $76,9 \%$ y una especificidad de $90,2 \%$.

El resto de variables se recogieron mediante un cuestionario estructurado con entrevistador. Los ítems de estos bloques se extrajeron de un estudio previo $^{12}$. Estos se agruparon en los siguientes bloques: sociodemográficas, variables clínicas, variables relacionadas con el medio penitenciario, variables de apoyo social, variables relacionadas con las drogas y variables relacionadas con la adhesión terapéutica.

\section{Procedimiento:}

Los datos necesarios para el estudio se obtuvieron gracias a las entrevistas concertadas por el equipo médico de los centros. Tras explicarles los objetivos del estudio y tras su incorporación voluntaria al mismo se les hizo firmar el consentimiento informado, en cumplimiento del artículo 8.1 del Reglamento Penitenciario. Igualmente se garantizó la confidencialidad de los datos. La administración de los cuestionarios se llevó a cabo por encuestadores adiestrados.

Teniendo en cuenta las características de la población diana, muchas de las preguntas se adecuaron a la jerga al uso.

Aunque los internos no tienen la obligación de realizarse la prueba del VIH, en nuestro medio esta prueba la suelen realizar todos los reclusos. Los valores de CD4 (citometría de flujo) y la carga viral (La técnica de medición utilizada fue el NASBA o PCR, según el centro) se extrajeron de las historias clínicas informatizadas y se tomaron los últimos valores disponibles.

\section{Análisis estadístico:}

Se llevó a cabo un análisis descriptivo usando los estadísticos habituales, media y desviación típica. $\mathrm{Pa}$ ra el análisis bivariante, para las variables independientes cualitativas se empleó la prueba de chi cuadrado o el test exacto de fisher, en el caso de las dicotómicas, cuando el porcentaje de frecuencia esperada inferior a 5 fue mayor del $30 \%$. Para las variables cuantitativas con comportamiento normal y homogeneidad de la varianza se empleó la prueba de t-Student. Para las demás variables se utilizó la prueba de U de Mann-Whitney. Se realizó a través del paquete estadístico SPSS 12.0.

\section{RESULTADOS}

De los 585 reclusos, 15 habían abandonado el tratamiento antirretroviral por los efectos adversos que 
este le producía. De los 570 restantes, el $56.3 \%$ estaban en TARV, al $26.8 \%$ no le estaba indicado y el $16.8 \%$ rehusaba tomarlo.

En lo referente a las características sociodemográficas, el grupo de reclusos que rehusaron el tratamiento presentó la mayor edad (37.45 años), el mayor porcentaje de hombres $(93.7 \%)$ y el mayor número de presos con hijos $(58.9 \%)$, mientras la menor edad (36.5 años) y mayor porcentaje de mujeres $(11.1 \%$ ) se encontraron entre aquellos a los que no se indicaba el tratamiento. En este último grupo además encontramos el nivel de estudios más elevado $(43.8 \%$ con estudios superiores a primarios). Ninguna de estas diferencias fue estadísticamente significativa.

Respecto a las variables relacionadas con las drogodependencias, el grupo de reclusos que rehusaron el tratamiento fue el que con mayor frecuencia consumía drogas antes de entrar en prisión (99\%), estaba más frecuentemente en tratamiento con metadona $(62.5 \%)(p=0.027)$ y en el que con mayor frecuencia se tomaba heroína y/o cocaína como droga más consumida tanto en la calle $(94.7 \%)$ como en prisión $(11.5 \%)(p=0.040)$. Entre aquellos a los que no se indicaba tratamiento antirretroviral se presentó tanto el menor consumo de drogas antes de entrar en prisión $(3.3 \%)$, como el menor consumo de heroína y/o cocaína como droga principal, tanto en la cárcel $(3.3 \%)$ como fuera de ella (88.5\%). El menor tiempo como consumidor de drogas se recoge entre los que toman antirretrovirales (17.71 años) (Tabla I).

Al comparar las variables relacionadas con la salud, los reclusos que rechazaron el tratamiento antirretroviral presentaron la cifra más baja de linfocitos CD4 (305.06, DS: 173) ( $\mathrm{p}<0.001)$, el menor porcentaje de personas con carga viral indetectable $(5.1 \%)$ $(\mathrm{p}<0.001)$, el mayor porcentaje de reclusos con peor salud autopercibida $(47.9 \%, \mathrm{p}<0.001)$ y mayor número de infectados por la hepatitis $\mathrm{C}(91.1 \%)(\mathrm{p}=0.003)$. Asimismo, aunque sin diferencias estadísticamente significativas, los pacientes que rehusaron el tratamiento presentaron la mayor prevalencia tanto de morbilidad psíquica $(65.9 \%)$ como de enfermedad crónica (91.1\%), y el mayor número de meses desde el diagnóstico de VIH (156.65). Por su parte, los reclusos que tomaban el tratamiento presentaron el mayor porcentaje de diagnósticos de SIDA (27.8\%) $(\mathrm{p}<0.001)$ y el mayor número de veces en tratamiento antirretroviral $(1.84)(\mathrm{p}<0.001)$, así como el mayor porcentaje de ingresos en los seis meses anteriores $(21.8 \%)$ y enfermedad tuberculosa $(8.4 \%)$, aunque sin significación estadística. Finalmente destacar que el grupo al que no se indicó tratamiento antirretroviral presentó la menor frecuencia de pacientes con morbilidad psíquica $(44.1 \%)$, sin experiencia previa al

\begin{tabular}{|c|c|c|c|c|c|}
\hline & & $\begin{array}{c}\text { tto. no indicado } \\
\mathrm{n}(\%)\end{array}$ & $\begin{array}{c}\text { toman tto. indicado } \\
\mathrm{n}(\%)\end{array}$ & $\begin{array}{c}\text { rehusan tto. } \\
\mathrm{n}(\%)\end{array}$ & $\mathrm{p}$ \\
\hline sexo & $\begin{array}{l}\text { hombre } \\
\text { mujer }\end{array}$ & $\begin{array}{c}136(88.9) \\
17(11.1) \\
\end{array}$ & $\begin{array}{r}296(92.2) \\
25(7.8) \\
\end{array}$ & $\begin{array}{c}90(93.7) \\
6(6.3) \\
\end{array}$ & $0.335^{*}$ \\
\hline hijos & \begin{tabular}{|l|} 
no \\
sí \\
\end{tabular} & $\begin{array}{l}66(43.1) \\
87(56.9) \\
\end{array}$ & $\begin{array}{l}148(46.1) \\
173(53.9) \\
\end{array}$ & $\begin{array}{l}39(41.1) \\
56(58.9) \\
\end{array}$ & $0.635^{*}$ \\
\hline estudios & $\begin{array}{l}\text { primarios sin acabar } \\
\text { primarios acabados }\end{array}$ & $\begin{array}{l}86(56.2) \\
67(43.8) \\
\end{array}$ & $\begin{array}{l}207(64.7) \\
113(35.3) \\
\end{array}$ & $\begin{array}{l}62(64.6) \\
34(35.4) \\
\end{array}$ & $0.182^{*}$ \\
\hline $\begin{array}{l}\text { consumo de } \\
\text { drogas en calle }\end{array}$ & $\begin{array}{l}\text { no } \\
\text { sí }\end{array}$ & $\begin{array}{c}5(3.3) \\
148(96.7)\end{array}$ & $\begin{array}{c}7(2.2) \\
304(97.8)\end{array}$ & $\begin{array}{c}1(1.0) \\
95(99.0)\end{array}$ & - \\
\hline $\begin{array}{l}\text { droga de más } \\
\text { consumo en calle }\end{array}$ & $\begin{array}{l}\text { heroína y/o cocaína } \\
\text { otras }\end{array}$ & $\begin{array}{l}131(88.5) \\
17(11.5)\end{array}$ & $\begin{array}{c}288(91.7) \\
26(8.3)\end{array}$ & $\begin{array}{c}90(94.7) \\
5(5.3)\end{array}$ & $0.229 *$ \\
\hline $\begin{array}{l}\text { tratamiento } \\
\text { metadona }\end{array}$ & \begin{tabular}{|l|} 
sí \\
no
\end{tabular} & $\begin{array}{l}72(47.1) \\
81(52.9)\end{array}$ & $\begin{array}{l}153(47.7) \\
168(52.3)\end{array}$ & $\begin{array}{l}60(62.5) \\
36(37.5)\end{array}$ & $0.027 *$ \\
\hline $\begin{array}{l}\text { consumo drogas } \\
\text { dentro de prisión }\end{array}$ & $\begin{array}{l}\text { heroína y/o cocaína } \\
\text { otras o metadona } \\
\text { ninguna }\end{array}$ & $\begin{array}{c}5(3.3) \\
89(58.2) \\
59(38.6) \\
\end{array}$ & $\begin{array}{c}14(4.4) \\
174(54.2) \\
133(41.4)\end{array}$ & $\begin{array}{l}11(11.5) \\
46(47.9) \\
39(40.6)\end{array}$ & $0.040^{*}$ \\
\hline & & media (d.s) & media (d.s) & media (d.s) & $\mathrm{p}$ \\
\hline edad (años) & & $36.50(5.48)$ & $37.17(5.32)$ & $37.45(5.46)$ & $0.320 * *$ \\
\hline tiempo como con & nidor de drogas & 18.62 & 17.71 & $18.50(6.87)$ & $0.328^{* *}$ \\
\hline
\end{tabular}

"Chi Cuadrado *ANOVA tto $=$ tratamiento $\mathrm{n}=$ número.

Tabla I: Variables sociodemográficas y relacionadas con drogodependencias. 


\begin{tabular}{|c|c|c|c|c|c|}
\hline & & $\begin{array}{c}\text { tto. no indicado } \\
\mathrm{n}(\%)\end{array}$ & $\begin{array}{c}\text { toman tto. indicado } \\
\mathrm{n}(\%)\end{array}$ & $\begin{array}{c}\text { rehusan tto. } \\
\mathrm{n}(\%)\end{array}$ & $\mathrm{p}$ \\
\hline salud autopercibida & $\begin{array}{l}\text { mejor } \\
\text { igual } \\
\text { peor }\end{array}$ & $\begin{array}{l}46(30.1) \\
59(38.6) \\
48(31.4)\end{array}$ & $\begin{array}{c}145(45.5) \\
67(21.0) \\
107(33.5)\end{array}$ & $\begin{array}{l}16(16.7) \\
34(35.4) \\
46(47.9)\end{array}$ & $<0.001^{*}$ \\
\hline morbilidad psíquica & $\begin{array}{ll}\text { sí } \\
\text { no }\end{array}$ & $\begin{array}{l}76(55.9) \\
60(44.1)\end{array}$ & $\begin{array}{l}184(61.7) \\
114(38.3)\end{array}$ & $\begin{array}{l}58(65.9) \\
30(31.3)\end{array}$ & $0.293^{*}$ \\
\hline enfermedad crónica & $\begin{array}{l}\text { sí } \\
\text { no }\end{array}$ & $\begin{array}{c}103(67.8) \\
49(32.2)\end{array}$ & $\begin{array}{l}236(74.4) \\
81(25.6)\end{array}$ & $\begin{array}{l}76(80.9) \\
18(19.1)\end{array}$ & $0.852^{*}$ \\
\hline tuberculosis & $\begin{array}{l}\text { sí } \\
\text { no }\end{array}$ & $\begin{array}{c}7(6.8) \\
96(93.2)\end{array}$ & $\begin{array}{c}20(8.4) \\
217(91.6)\end{array}$ & $\begin{array}{c}6(7.9) \\
70(92.1)\end{array}$ & 0.876 \\
\hline Hepatitis c & $\begin{array}{l}\text { sí } \\
\text { no }\end{array}$ & $\begin{array}{l}112(77.8) \\
32(22.2)\end{array}$ & $\begin{array}{l}258(88.4) \\
34(11.6)\end{array}$ & $\begin{array}{c}82(91.1) \\
8(8.9)\end{array}$ & $0.003 *$ \\
\hline sida & $\begin{array}{l}\text { sí } \\
\text { no }\end{array}$ & $\begin{array}{c}5(3.4) \\
141(96.6)\end{array}$ & $\begin{array}{c}86(27.8) \\
223(72.2)\end{array}$ & $\begin{array}{l}21(22.6) \\
72(77.4)\end{array}$ & $<0.001 *$ \\
\hline $\begin{array}{l}\text { ingreso previos seis } \\
\text { meses }\end{array}$ & $\begin{array}{ll}\text { sí } \\
\text { no }\end{array}$ & $\begin{array}{c}29(19.0) \\
124(81.0)\end{array}$ & $\begin{array}{c}70(21.8) \\
251(78.2)\end{array}$ & $\begin{array}{l}20(20.8) \\
76(79.2)\end{array}$ & $0.775^{*}$ \\
\hline carga viral & $\begin{array}{l}\text { indetectable } \\
<50000 \text { copias } \\
>50000 \text { copias }\end{array}$ & $\begin{array}{l}25(19.1) \\
86(65.6) \\
20(15.3)\end{array}$ & $\begin{array}{c}164(60.3) \\
83(30.5) \\
25(9.2)\end{array}$ & $\begin{array}{c}4(5.1) \\
45(57.7) \\
29(37.2)\end{array}$ & $<0.001 *$ \\
\hline $\begin{array}{l}\text { alguna vez en tratamiento } \\
\text { antirretroviral }\end{array}$ & $\begin{array}{l}\text { Sí } \\
\text { No }\end{array}$ & $\begin{array}{c}0(0 \%) \\
321(100 \%)\end{array}$ & $\begin{array}{c}115(75,2 \%) \\
38(24,8 \%)\end{array}$ & $\begin{array}{l}39(40,6 \%) \\
57(59,4 \%)\end{array}$ & $<0.001 *$ \\
\hline \multirow{2}{*}{\multicolumn{2}{|c|}{ cd4 (céls $\left./ \mathrm{mm}^{3}\right)$}} & media(d.s) & media(d.s) & media(d.s) & $\mathrm{p}$ \\
\hline & & $611.7(288.34)$ & $380.8(237.33)$ & $305.06(173.21)$ & $<0.001 * *$ \\
\hline \multicolumn{2}{|c|}{$\mathrm{n}^{\circ}$ de veces en tratamiento antirretroviral } & $0.36(0.827)$ & $1.84(1.225)$ & $1.69(2.25)$ & $<0.001 * *$ \\
\hline \multicolumn{2}{|c|}{ meses desde detección anticuerpos } & $142.52(71.53)$ & $150.23(64.92)$ & $156.65(68.96)$ & $0.191 * *$ \\
\hline
\end{tabular}

"Chi Cuadrado **ANOVA tto $=$ tratamiento $\mathrm{n}=$ número.

Tabla II: Variables relacionadas con la salud.

tratamiento antirretroviral $(76.2 \%)$, enfermedad crónica (32.2\%), hepatitis C (22.2\%) y SIDA (3.4\%), así como el mayor número medio de linfocitos $\mathrm{CD} 4$ (611.7 Cel/ $\mathrm{mm}^{3}$ ) (Tabla II).

Por último, en relación a las variables propias de la cárcel, los reclusos que rehusaron el tratamiento antirretroviral eran los que presentaban con mayor frecuencia juicios pendientes (22.9\%), más de dos entradas en prisión $(86.5 \%)$ y apoyo social externo (95.8\%); eran el grupo con más pacientes con visitas recibidas $(67.7 \%)$, y los que tenían tanto un mayor tiempo de condena (61.93 meses), como a los que quedaba mayor tiempo en prisión (30.61 meses). Por el contrario fueron los que con menor frecuencia tenían destino en prisión (41.1\%) y los que menor apoyo social dentro de la cárcel perciben $(39.6 \%)$. Ninguna de estas diferencias fue estadísticamente significativa. Destacar por último, que entre aquellos a los que no se indicó tratamiento antirretroviral se dio con mayor frecuencia la situación de prisión preventiva $(5.2 \%)$ (Tabla III).

\section{DISCUSIÓN}

En la investigación sobre el paciente seropositivo son pocos los temas que quedan por estudiar. Han sido tratados de una u otra manera desde los aspectos más centrados en las características clínicas de la infección a los factores sociales del individuo. Lo que sí se mantiene homogéneo es el tipo de población sobre la que versan estos estudios. Por las características de la mayor parte de los mismos, las muestras parten de grupos que se encuentran en seguimiento clínico, o como mínimo sobre los que se realiza algún tipo de intervención asistencial. Esto deja un reducto importante de pacientes sin conocer. Aquellos pacientes sobre los que no se realiza ninguna intervención por ser éstos los que renuncian a ella.

Las investigaciones realizadas a pacientes VIH+ en el medio penitenciario, han supuesto la incorporación a los estudios de pacientes que de ninguna otra manera se hubieran podido captar en otro tipo de medio. Además cabe destacar que no se han encontrado 


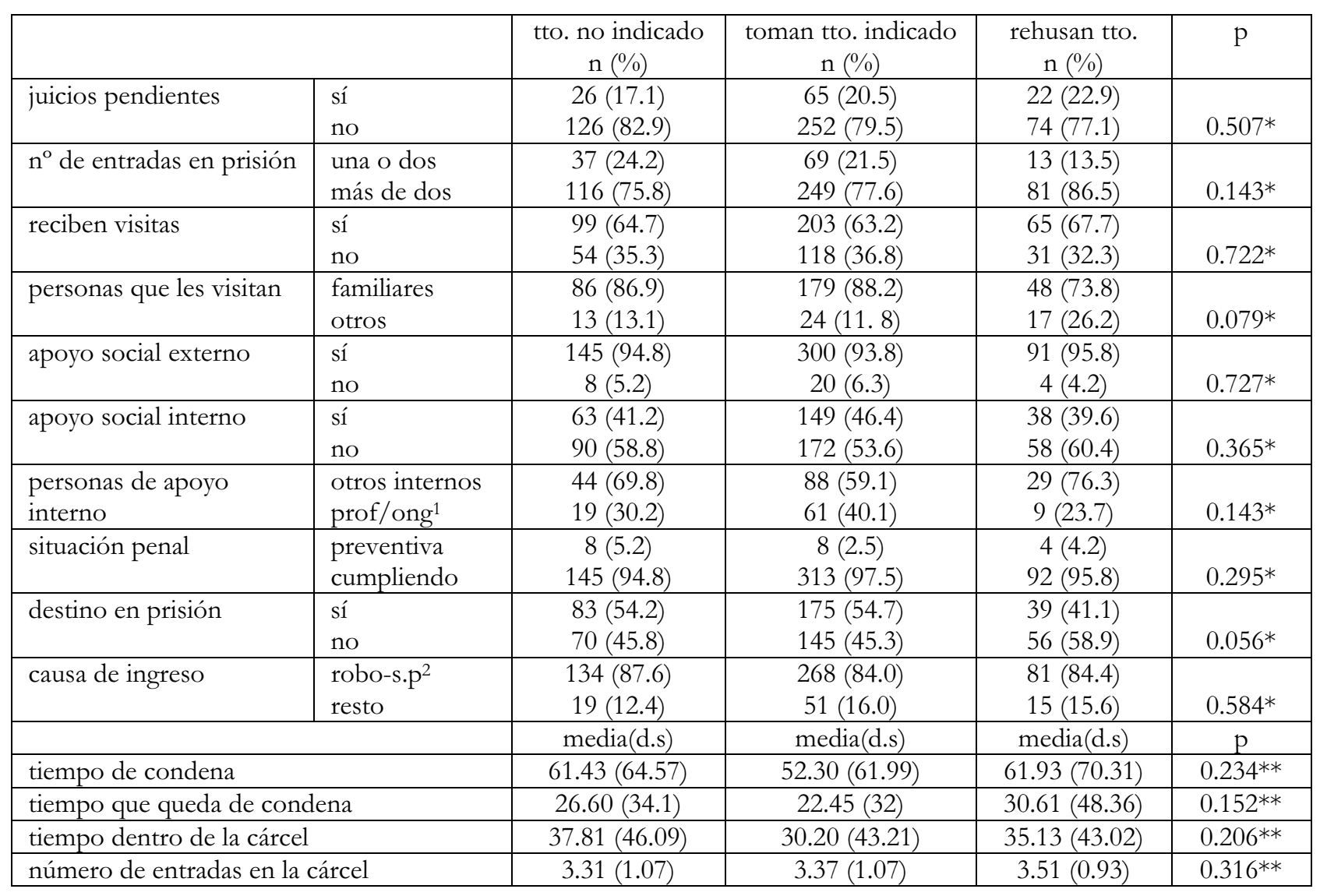

${ }^{1}$ Profesionales del centro penitenciario o trabajadores de ONGs. ${ }^{2}$ Condena por robo o delitos contra la salud pública.

"Chi Cuadrado **ANOVA tto $=$ tratamiento $\mathrm{n}=$ número.

Tabla III: Variables específicas del medio penitenciario

estudios que se centren a nivel asistencial en aquellos pacientes infectados por el VIH, que por algún motivo, decidan rehusar el tratamiento antirretroviral. Este estudio pretende ser un punto de inicio para considerar las características diferenciales del grupo que rehúsa el tratamiento.

Respecto a las limitaciones del presente estudio, debemos tener en cuenta la posibilidad de que los pacientes con una peor salud se encontrasen ingresados en el momento del estudio. Este hecho podría afectar especialmente a los pacientes que rehusaban el tratamiento. En relación al TARV, en las tres cárceles los criterios en los que se basa la puesta en tratamiento son los mismos ${ }^{7}$, aunque cada caso ha sido estudiado individualmente, por lo que es innegable la posibilidad de cierta variabilidad a la hora de recomendar o no el tratamiento antirretroviral.

La población objeto de este estudio es aquella que rehúsa el tratamiento. Lo que podría generar dudas es la división del resto de pacientes en dos subgrupos, los que están en tratamiento y los que no, ya que en ambos casos lo hacen siguiendo consejo facultativo. Unir a estos grupos en uno sólo podría llevar a cometer el error de no diferenciar entre dos grupos con variables clínicas diferentes, que precisamente condicionan que se les prescriba o no tratamiento antirretroviral.

El perfil de esta muestra de reclusos que rechazan el tratamiento coincide tanto con el perfil de la población reclusa VIH+ española y la de otros países, como con la del resto de los subgrupos de este estudio: fundamentalmente hombres, con una media de edad en torno a 35 años, con estudios previos básicos y muy pocos en situación de prisión preventiva ${ }^{3,9,13,14}$.

En relación al consumo de drogas, esta muestra presenta una mayor prevalencia de consumo tanto si la comparamos con estudios realizados en población general reclusa ${ }^{17}$, como con seropositivos del medio penitenciario $^{18}$.

En este mismo sentido, en prisión, el grupo que rehúsa TARV presenta el mayor consumo de opiá- 
ceos y cocaína, y prescripción de metadona. Teniendo en cuenta que dentro de la cárcel disminuye el consumo de sustancias ${ }^{4}$, lo cual ayuda a una mejor reinserción por parte del preso a la sociedad, quizá fuesen necesarias intervenciones específicas entre esta población que pudieran apoyarse en las infraestructuras ya existentes en torno a la metadona.

Las diferencias en los parámetros que miden la salud de los tres grupos tienen diferentes interpretaciones. Tanto la carga viral, el nivel de CD4 y el estadio SIDA son parámetros que determinan la decisión del facultativo de recomendar TARGA, por lo que es lógico que en los grupos de rehusantes y en tratamiento sus cifras y porcentajes sean similares, y a su vez difieran de los del grupo al que no se indica TARGA. El que la salud autopercibida sea peor en los rehusantes, teniendo en cuenta la transversalidad del estudio, tiene dos posibles explicaciones. El no estar en TARGA pudiera condicionar una peor salud autopercibida o percibir una mala salud pudiera determinar rehusar el TARGA. En cualquier caso, es un grupo que se percibe con una peor salud, en la misma línea que ya se ha hecho mención de las repercusiones que rehusar el TARV tiene sobre la calidad de vida ${ }^{20}$.

En relación a la coinfección con VHC, aquellos que rehúsan muestran una mayor prevalencia de coinfección que la población seropositiva intra y extrapenitenciaria ${ }^{13,21,23}$. Quizá sea esta coinfección y la sobrecarga terapéutica consiguiente una de las causas de que estos pacientes rechacen el tratamiento antirretroviral. Es importante proseguir esta línea de investigación, ya que son muchos los estudios que hablan de diferencias importantes en la evolución y pronóstico de los pacientes seropositivos con $\mathrm{VHC}^{21,22}$.

La literatura indica que la presencia de morbilidad psíquica en la población penitenciaria es superior que en la población general. En nuestro estudio, el grupo de los pacientes que rehúsan, presenta una prevalencia de morbilidad psíquica algo superior a la de los otros dos grupos, y sensiblemente superior a la prevalencia de la misma en prisiones ${ }^{24,25}$. Este hecho plantea la necesidad de una evaluación psicológica individualizada de estos pacientes, como parte de su cuidado.

Respecto a las variables propias del medio penitenciario, llama la atención que el recluso seropositivo presenta una mayor frecuencia de reingreso en prisión que el resto de la población penitenciaria ${ }^{4,9}$, quizás por el mayor consumo de drogas. Y si de esta población tan sólo tomamos a los que rehúsan el TARV, el porcentaje de reclusos que han estado más de dos veces en prisión triplica al de la población general ${ }^{4}$. Además este grupo de pacientes rehusantes muestra una peor situación en la cárcel (mayor número de entradas, juicios pendientes, menor tiempo de condena cumplido y tiempo de condena restante). Todo ello, sin poder determinar si estos datos son causa o efecto de su rechazo al tratamiento, dibuja un perfil de qué tipo de pacientes son los que rehúsan el tratamiento. En este medio estamos hablando de un grupo que reincide en los delitos y no llega a integrarse en la sociedad. Quizá sea el momento de comenzar a diseñar intervenciones pensando tanto en su día a día en el medio penitenciario como en el momento en el que cumplen sus penas. Independientemente de ello, se han realizado estudios que remarcan la importancia que factores propios de las prisiones juegan sobre el preso seropositivo en la adherencia ${ }^{8}$. Sería interesante evaluar la importancia que estos factores propios tienen sobre la negativa de estos pacientes a tomar TARV.

En resumen, los resultados de este estudio ponen de manifiesto las diferencias que existen entre poblaciones seropositivas según sigan o no las recomendaciones de sus médicos. Existe un grupo de pacientes, ignorado en la mayor parte de los estudios, que rechaza el tratamiento antirretroviral y al que podemos acceder en el medio penitenciario. Este grupo tiene características diferenciales, tales como una mayor prevalencia de coinfección por VHC, un mayor consumo intrapenitenciario de opiáceos o un menor trabajo como destino en prisión, y por tanto debemos ajustar las intervenciones que se realicen sobre ellos.

\section{AGRADECIMIENTOS}

Este estudio está financiado por la Consejería de Salud de la junta de Andalucía. Exp. 82/03 y parcialmente por la Red de centros en Epidemiología y Salud Pública (RCESP C03/09).

\section{BIBLIOGRAFÍA}

1. Lucas GM, Chaisson RE, Moore RD. Survival in an Urban HIV-1 Clinic in the Era of Highly Active Antiretroviral Therapy: A 5-year Cohort Study. J Acquir Imm Defic Syndr. 2003; 33: 321-328.

2. García de Olalla P, Knobel H, Carmona A, Guelar A, López Colomer JL, Caylá JA. Impact of adherence and HAART on survival in HIV-infected patients. J Acquir Imm Defic Syndr. 2002; 30: 105-10.

3. Gabinete técnico de la dirección general de instituciones penitenciarias. Ministerio del interior. Datos estadísticos de la población reclusa. Abril 
de 2006. [Consultado el 26 de julio de 2007]: Disponible en http://www.mir.es/instpeni/archivos/ mensual.pdf.

4. Encuesta estatal sobre salud y drogas entre los internados en prisión (ESDIP) 2006. Dirección General de Atención a las Drogodependencias.

5. Informe General 2003. Dirección General de Instituciones Penitenciarias. Ministerio del interior.

6. Grupo castellano-leonés para la infección de VIH en prisiones. Estudio sobre casos de infección VIH en prisiones de Castilla y León. Rev Clin Esp. 2001; 201: 249-55.

7. Recomendaciones de GESIDA/Plan Nacional sobre el SIDA respecto al tratamiento antirretroviral en adultos infectados por el virus de la inmunodeficiencia humana (actualización enero de 2007). Enferm Infecc Microbiol Clin. 2007; 25: 32-53.

8. Soto JM, Ruiz I, March JC. Adherence to antiretroviral therapy among HIV-infected prison inmates (Spain). Int J STD AIDS. 2005; 16: 133-138.

9. Olry de Labry A, Plazaola J, Ruiz I, Soto JM, Antón JJ, Castro JM, Girela E. Estado clínico y psicosocial de reclusos en tratamiento con antirretrovirales. Rev Esp Sanid Penit. 2003; 5: 92-100.

10. Artículo 104.4 Reglamento Penitenciario. Real Decreto 190/1996, de 9 de febrero. Boletín Oficial del Estado. núm. 40 de 15 de febrero de 1996.

11. Knobel H, Alonso J, Casado JL, Collazos J, González J, Ruiz I, et al. Validation of a simplified medication adherence questionnaire in a large cohort of HIV-infected patients: the GEEMA study. AIDS. 2002; 16: 605-613.

12. Muñoz PE, Tejerina-Allen M, Cañas F. estudio de validación preactiva del GHQ en población general urbana. Beca FIS 93/0905. Sin publicar.

13. Kindelán JM, del Amo J, Martín C, Sáiz de la Hoya P, Pulido F, Laguna F. Tratamiento de la infección por VIH en pacientes con problemática psicosocial. Enferm Infecc Microbiol Clin. 2002; 20 (Supl 2): 19-28.

14. Baillargeon J, Borucki M, Zepeda S, Jenson H, Leach C. Antiretroviral prescribing patterns in the Texas prison system. Clin Infec Dis. 2000; 31: 476-81.

15. Carpenter CC, Fischl MA, Hammer SM, Hirsch MS, Jacobsen DJ, Katzenstein DA et al. Antiretroviral therapy for HIV infection in 1998, updated recommendations of the International AIDS Society - USA Panel. JAMA. 280: 1: 78-86.

16. Blanco JM, Ruiz-Pérez I, Olry de Labry Lima A, Recio JM, López EG, Basanta JJ.Adherence to antiretroviral treatment in prisons. AIDS Res Hum Retroviruses. 2005; 21 (8): 683-8.
17. Oviedo-Joekes E, March-Cerda JC, RamosMontserrat MJ, Ballesta-Gómez R, Prieto Rodríguez MA. Percepción del estado de salud y utilización de servicios sanitarios por parte de las personas internas en una prisión andaluza, 1999. Rev Esp. Salud Publica. 2005; 79: 35-46.

18. Goldstein RB, Johnson MO, Rotheram-Borus MJ, Kirshenbaum SB, Pinto RM, Kittel L, Pequegnat W, Mickalian JD, Weinhardt LS, Kelly JA, Lightfoot M; National Institute Mental Health Healthy Living Project Psychological distress, substance use, and adjustment among parents living with HIV. J Am Board Fam Pract. 2005; 18: 362-73.

19. European Centre for the Epidemiolgical Monitoring of AIDS. HIV/AIDS Surveillance in Europe. End-year report 2004. Saint-Maurice: Institut de veille sanìtaire, 2005. No. 71 [Consultado el 31/07/2007]. Disponible en: www.eurohiv.org/ reports/report_71/pdf/report_eurohiv_71.pdf].

20. Sordo del Castillo L, Olry de Labry Lima A, Ruiz Pérez I, Soto Blanco JM, Girela López E, Castro Recio JM, Antón Basanta JJ. Influence of antiretroviral treatment on quality of life in seropositives inmates. Int J STD AIDS. (en prensa).

21. Saiz de la Hoya P, Bedia M, Murcia J, Cebria J, Sanchez-Paya J, Portilla J. Predictive markers of $\mathrm{HIV}$ and HCV infection and co-infection among inmates in a Spanish prison. Enferm Infecc Microbiol Clin. 2005; 23 (2): 53-7.

22. Soriano V, Gonzalez-Lahoz J. Hepatitis C y VIH en prisiones españolas. Enferm Infecc Microbiol Clin. 2005; 23: 51-2.

23. López-Caleya JF, Martín V, Martín L, Pérez-Simón R, Carro JA, Alcoba M. Prevalence of coinfection by human immunodeficiency virus and hepatitis C virus in the Leon Health Area: 19922000. Enferm Infecc Microbiol Clin. 2006; 24: 365-369.

24. Fazel S, Danesh J. Serious disorder in 23000 prisioners: a sistematic review of 62 surveys. Lancet. 2002; 359: 545-50.

25. Brinded PM, Simpson A, Laidlaw T, Fairley N, Malcolm F. Prevalence of psychiatric disorders in New Zealand prisons: nacional study. Aust N Z J Psychiatric. 2001; 35: 166-73.

\section{CORRESPONDENCIA}

Talleres Editoriales Cometa, S.A.

Ctra. Castellón, km. 3,400.

50013 Zaragoza. 